\section{Detection of clonal immunoglobulin gene rearrangements in the peripheral blood progenitor cells of patients with multiple myeloma: the potential role of purging with CD34 positive selection}

R G Owen, A P Haynes, P A Evans, R J Johnson, A C Rawstron, G McQuaker, G M Smith, M C Galvin, D L Barnard, N H Russell, J A Child, G J Morgan

\begin{abstract}
Aims-To determine the extent of clonal cell contamination of peripheral blood progenitor cell (PBPC) collections in patients with multiple myeloma (MM) and to assess the purging efficacy of $\mathrm{CD} 34$ positive selection.
\end{abstract}

Methods-PBPC collections from 29 patients with $M M$ were analysed for the presence of clonal immunoglobulin heavy chain (IgH) gene rearrangements with a dition, the PBPC from eight of the 29 patients were "purged" by selection of CD34 positive haematopoietic progenitors with an avidin-biotin immunoabsorption column (Ceprate). In each case the unmanipulated PBPC, CD34 positive and waste fractions were all assessed for the presence of clonal IgH rearrangements.

Results-Clonal IgH rearrangements (identical with those demonstrated in diagnostic bone marrow samples) were demonstrated in $10(35 \%)$ of 29 cases and seemed to be confined to those with significant residual bone marrow disease. Clonal rearrangements were evident in the PBPC of two of the eight patients who underwent CD34 selection; in both instances a "clonal purge" was seen as it was not possible to demonstrate the clonal rearrangement in the $\mathrm{CD} 34$ positive fraction. In four of the six remaining cases the normal polyclonal fingerprint could not be demonstrated in the CD34 positive fraction, which is consistent with a significant reduction in contaminating $B$ cells.

Conclusions-Clonal cells contaminate PBPC collections in a significant proportion of patients with $M M$ and may be eliminated by CD34 positive selection. (F Clin Pathol: Mol Pathol 1996;49:M112-M117)

Keywords: PCR, peripheral blood progenitor cells, myeloma, CD34, purging.

The use of peripheral blood progenitor cells (PBPC) has largely superseded that of autologous marrow in the support of high dose chemo-radiotherapy. This change in practice has occurred mainly as a result of the significant fluorescence based PCR technique. In ad- engraftment advantage of PBPC, which in turn has resulted in a reduction in treatment related mortality. High dose therapy with autologous stem cell support can induce complete reand early data suggest that this may translate into a survival advantage. ${ }^{2}$ However, relapse remains the norm following autologous transplantation and it is unclear whether this is a result of residual disease within the patient or re-infused tumour cells, or both.

It was perceived originally that PBPC would be free from tumour cell contamination. Recently, however, clonal gene rearrangements (suggesting the presence of contaminating tumour cells) have been demonstrated in the PBPC of patients with multiple myeloma ${ }^{3}$ and non-Hodgkin's lymphoma. ${ }^{4}$ In addition, tumour cells have been directly demonstrated in the PBPC of patients with solid tumours. ${ }^{5}$ These data suggest a need for purging strategies such as the positive selection of haematopoietic progenitors by virtue of their CD34 expression. Such selection strategies require detailed evaluation. In particular, the purging efficacy should be assessed with sensitive PCR based techniques capable of detecting the clone when it is present at very low levels.

\section{Methods} the IgH PCR in plasma cell dyscrasias, we analysed diagnostic bone marrow from 129 patients with multiple myeloma and 15 patients with monoclonal gammopathy of undetermined significance (MGUS). Peripheral blood samples were also obtained from 44 patients with multiple myeloma (prior to the initiation of chemotherapy) and from eight patients with MGUS. Each peripheral blood sample was assessed for the presence of an IgH rearrangement identical with that seen in the corresponding bone marrow sample.

PBPC collections were obtained from 29 patients; the majority (27/29) were chemosensitive (two CR1, 20 PR1, five PR2) while two had disease refractory to VAMP (vincristine, adriamycin and methyl prednisolone) chemotherapy. In all cases PBPC were mobilised following the completion of chemomission in up to $50 \%$ of patients with myeloma ${ }^{1}$

In order to assess the overall applicability of 

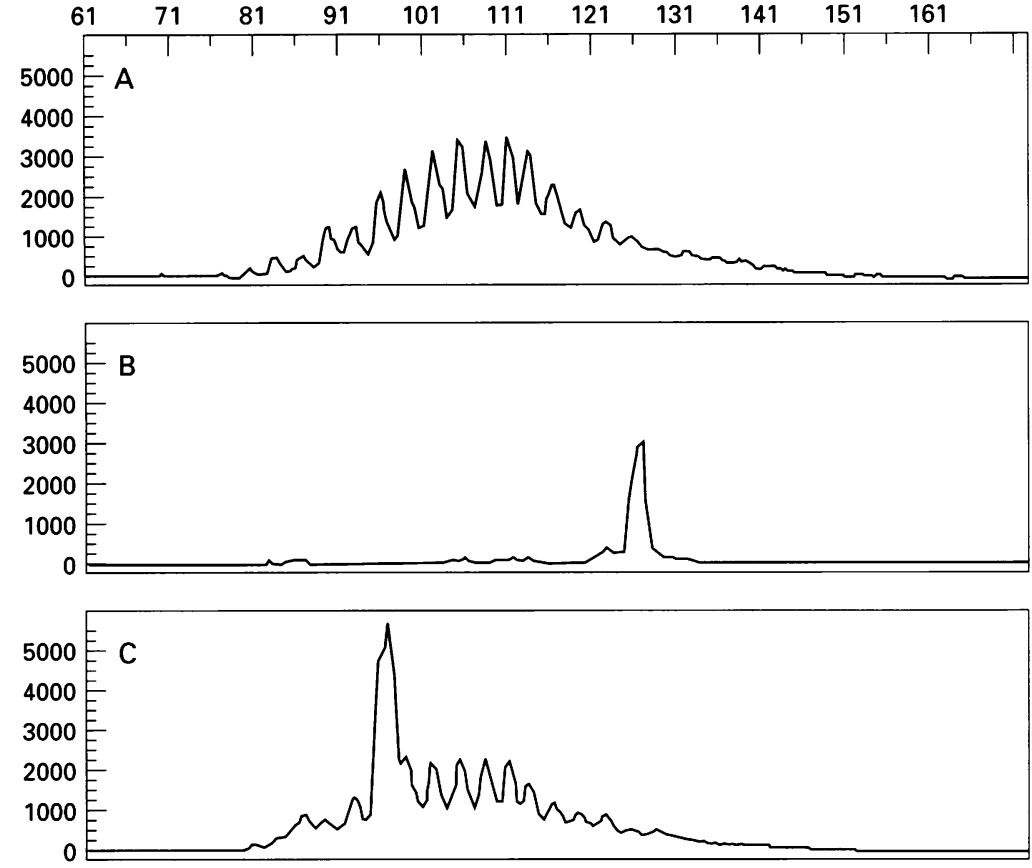

Figure 1 The typical "electrophoretogram" patterns generated by the computer software. Fluorescence intensity is represented on the vertical axis and the peak sizes (bp) on the horizontal axis. A polyclonal pattern or "fingerprint" $(A)$ consists of a number of peaks separated by 3 bp and arranged in a normal distribution. Clonal rearrangements may appear alone (B) or within a polyclonal background $(C)$.

therapy, with a regimen consisting of cyclophosphamide $\left(1 \cdot 5-3 \mathrm{~g} / \mathrm{m}^{2}\right)$ and G-CSF $5 \mathrm{mg} /$ $\mathrm{kg}$ (commenced on day +1 or day +5 ). Chemotherapy comprised 20 C-VAMP (cyclophosphamide-VAMP), 7 VAMP, 1 VAD (vincristine, adriamycin and dexamethasone), and 1 VBMCP (vincristine, BCNU, melphalan, cyclophosphamide and prednisolone). Leucapheresis was initiated when the peripheral blood white cell count was rising through $5 \times 10^{9} / 1$, typically on day +8 to day +10 . A total of 75 leucapheresis products were obtained from the 29 patients and each was assessed for the presence of an $\operatorname{IgH}$ rearrangement identical with that demonstrated in corresponding diagnostic bone marrow samples. In addition, remission bone marrow was assessed morphologically in all patients and peripheral blood samples were obtained prior to PBPC mobilisation and were assessed for the presence of $\mathrm{IgH}$ rearrangements in 23 of 29 patients.

\section{CD34 POSITIVE SELECTION}

This was performed using an avidin-biotin immunoabsorption column in eight of 29 patients. Briefly, PBPC obtained by leucapheresis carried out on consecutive days were pooled, washed and incubated with a biotinylated $\operatorname{IgM}$ anti-CD34. The antibody treated cells were washed and passed through the Ceprate column (Cellpro, Bothell, Washington, USA) containing $20 \mathrm{ml}$ avidin-biogel, which had been primed with saline and human albumin solution. The unbound cells were flushed from the column and the CD34 positive fraction released by gentle agitation with an internal magnetic stir bar. In all cases the unmanip- ulated PBPC, CD34 positive and waste fractions were assessed for the presence of $\mathrm{IgH}$ rearrangements.

DNA PREPARATION

High molecular weight DNA was obtained from presentation bone marrow (fresh samples or stored slides), fresh peripheral blood and aliquots of cryopreserved PBPC by proteinase $\mathrm{K}$ digestion, phenol-chloroform extraction and cold ethanol precipitation.

\section{FLUORESCENCE IgH PCR}

Clonal IgH rearrangements were demonstrated in presentation bone marrow samples using the CDR111 and CDR1 PCR techniques. Both utilise a consensus JH primer (5'-ACCTGAGGAGACGGTGACCAGGGT-3') which was 5 '-end labelled (via an aminohexyl link) with a green fluorochrome. The CDRIII PCR utilises a second consensus primer from the framework 3 region of the gene (5'-CCGAGGACACGGC(CT)(CG)TGTATTA CTG-3'). All samples were analysed using this technique; if the result was polyclonal or amplification unsatisfactory the CDRI PCR was used. This requires six reactions each using a family specific $\mathrm{VH}$ primer from the framework 1 region (VH1: 5'-CCTCAGTGAAGGTCTCCTGCAAGG-3'; VH2: 5'-GAGTCTGGTCCTGCGCT GGTGAAA-3'; VH3: 5'-GGTCCCTGAGACTCTCCTGTGCA-3'; VH4: 5'TTCGG A(GC)ACCCTGTCCC TCACCT3'; VH5: 5'-AGGTGAAAAAGCCCGGGAGTCT-3'; VH6: 5'-CCTGTGCCATCTCCGGGGACAGTG-3') in addition to the fluorescently labelled $\mathrm{JH}$ primer. The peripheral blood and PBPC samples were analysed with primers appropriate for their known rearrangements. The PCR reactions were carried out in $25 \mu \mathrm{l}$ volumes with $1 \mu \mathrm{g}$ DNA, 10 pmoles sense and antisense primers in buffer containing $10 \mathrm{mM}$ Tris (pH 9.1), $500 \mathrm{mM} \mathrm{KCl}$, $0.25 \mathrm{mM}$ each dATP, dCTP, dGTP, dTTP, $1.5 \mathrm{mM} \mathrm{MgCl}_{2}, 1 \%$ Triton $\mathrm{X}$, and $1 \%$ gelatin. The reaction mixtures were held at $95^{\circ} \mathrm{C}$ prior to the addition of 1 unit of Taq polymerase (SuperTaq, HT Biotechnology Ltd, Cambridge, UK). CDRIII PCR amplification conditions were: $95^{\circ} \mathrm{C}$ for one minute and $60^{\circ} \mathrm{C}$ for 90 seconds for a total of 35 cycles, followed by 10 minutes at $72^{\circ} \mathrm{C}$. The CDRI PCR amplification conditions were: $95^{\circ} \mathrm{C}$ for one minute, $68^{\circ} \mathrm{C}$ for one minute (reduced by $1^{\circ} \mathrm{C}$ in consecutive cycles to $62^{\circ} \mathrm{C}$ ) and $72^{\circ} \mathrm{C}$ for one minute for a total of 35 cycles, followed by $72^{\circ} \mathrm{C}$ for 10 minutes. The products of PCR amplification were then analysed as follows: $1 \mu \mathrm{l}$ of each PCR product was added to $4 \mu \mathrm{l}$ of loading mixture $(3 \mu \mathrm{l}$ formamide, $0.5 \mu \mathrm{l}$ red fluorochrome labelled size standard (GS 2500 ROX, Applied Biosystems) and $0.5 \mu$ ldextran blue). Each mixture was then denatured at $95^{\circ} \mathrm{C}$ for three minutes and held at $4{ }^{\circ} \mathrm{C}$ prior to loading onto $6 \%$ polyacrylamide gels. These were then analysed using an Applied Biosystems DNA sequencer (model 373A). The associated 

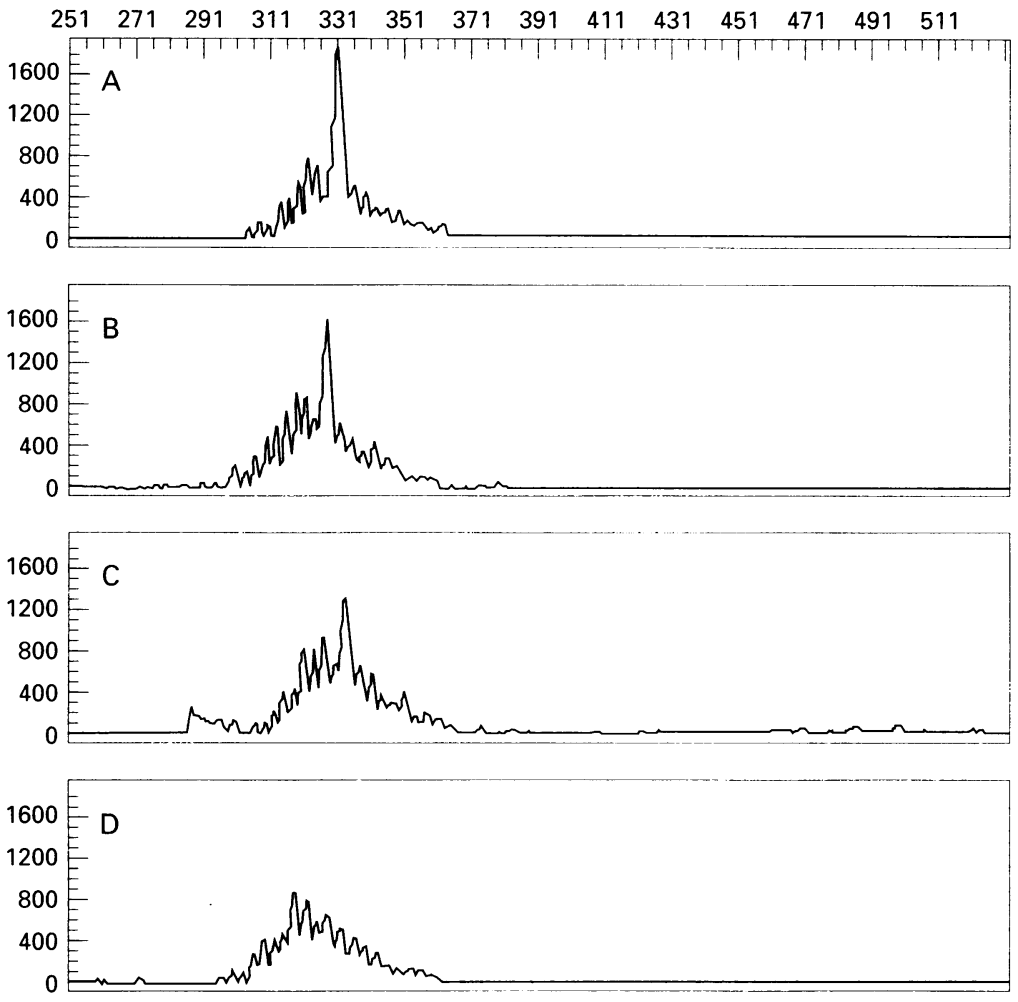

Figure 2 Demonstration of sensitivity (CDR1 PCR): clonal cells have been mixed with normal peripheral blood mononuclear cells at dilutions of 1 in $1000(A), 1$ in 10000 (B), 1 in $50000(C)$, and 1 in 100000 (D). The clonal rearrangement can be clearly seen in (B) but not in (D). An equivocal result is obtained in (C).

collection and analysis software converts the fluorescent gel image for each sample into an "electrophoretogram", which consists of a variable number of peaks whose height correspond to the intensity of fluorescence on the gel. A polyclonal pattern appears as a number of peaks separated by 3 base pairs (bp) and arranged in a normal distribution. Clonal rearrangements appear as distinct peaks either alone or within a polyclonal background (fig 1). The software is able consistently to size rearrangements to within a single bp and is also able to size each peak within a polyclonal population, which greatly facilitates the identification of clonal rearrangements of known sizes when they are present within a polyclonal background.

By diluting clonal B cells into normal peripheral blood mononuclear cells we have shown that these techniques are capable of detecting one clonal cell in a background of $10^{3}-10^{4}$ normal cells (fig 2). The CDRI PCR is $0 \cdot 5-1$ log more sensitive than the CDR111 PCR in the majority of cases.

\section{Results}

By utilising a combination of both the CDR111 and CDR1 PCR techniques, it was possible to demonstrate clonal $\mathrm{IgH}$ rearrangements in the presentation bone marrow samples of 97 (75\%) of 129 patients with multiple myeloma and 11 (73\%) of 15 patients with MGUS.

When the peripheral blood of patients presenting with myeloma was analysed clonal rearrangements were detected in $21(48 \%)$ of 44 patients. These were identical in size with those seen in the presentation bone marrow. Clonal rearrangements were also detected in the peripheral blood of two (25\%) of eight patients with MGUS.

The PBPC collections from an additional 29 patients with multiple myeloma were assessed for the presence of clonal IgH rearrangements.

Table 1 Results of IgH PCR analysis of PBPC in 29 patients with multiple myeloma. Note that patients 1-13 have significant residual bone marrow disease (see below); clonal IgH rearrangements were detected in the PBPC of 10 of 13 cases. Clonal rearrangements were not detected in the remaining 16 patients who had $<5 \%$ plasma cells in their bone marrow at time of mobilisation

\begin{tabular}{|c|c|c|c|c|c|c|c|c|}
\hline $\begin{array}{l}\text { Case } \\
\text { number }\end{array}$ & Status & $\% P C$ & $P C R$ & $P B$ & Day 1 & Day 2 & Day 3 & Day 4 \\
\hline 1 & Ref & $26 \%$ & FR3 + & NA & + & + & & \\
\hline 2 & Ref & $26 \%$ & FR3 + & NA & + & + & . & \\
\hline 3 & PRI & $20 \%$ & FR3 + & - & + & + & & \\
\hline 4 & PR2 & $19 \%$ & FR3 + & - & - & - & + & \\
\hline 5 & PR2 & $18 \%$ & FR3 + & - & - & + & & \\
\hline 6 & PR2 & $15 \%$ & $\mathrm{FR} 1+$ & -- & + & + & + & \\
\hline 7 & PR2 & $10 \%$ & $\mathrm{FR} 1+$ & - & + & + & + & t \\
\hline 8 & PR1 & $6 \% *$ & $\mathrm{FR} 1+$ & NA & + & + & - & \\
\hline 9 & PR1 & $<5 \% *$ & $\mathrm{FRl}+$ & NA & + & + & & \\
\hline 10 & PR1 & $<5 \% *$ & FR3 + & NA & + & + & + & + \\
\hline 11 & PR1 & $30 \%$ & FR3 + & - & - & - & - & \\
\hline 12 & PR1 & $27 \%$ & $\mathrm{FRl}+$ & - & - & - & - & - \\
\hline 13 & PR2 & $10 \%$ & FR3 + & - & - & & & \\
\hline 14 & PR1 & $6 \%$ & FR3 + & -- & - & - & - & \\
\hline 15 & PR1 & $<5 \%$ & $\mathrm{FRl}+$ & - & - & - & - & \\
\hline 16 & PRl & $<5 \%$ & $\mathrm{FR} 3+$ & - & - & & & \\
\hline 17 & PRI & $<5 \%$ & FR3 + & - & - & - & & \\
\hline 18 & PR1 & $<5 \%$ & FR3 + & - & - & & & \\
\hline 19 & PR1 & $<5 \%$ & $\mathrm{FR} 1+$ & - & - & - & - & \\
\hline 20 & PR1 & $<5 \%$ & $\mathrm{FR} 1+$ & - & - & - & & \\
\hline 21 & PR1 & $<5 \%$ & FR3 + & - & - & - & - & \\
\hline 22 & PR1 & $<5 \%$ & $\mathrm{FRl}+$ & - & - & - & - & \\
\hline 23 & PR1 & $<5 \%$ & $\mathrm{FR} 1+$ & - & - & - & - & \\
\hline 24 & PR1 & $<5 \%$ & FR3 + & - & - & - & & \\
\hline 25 & PR1 & $<5 \%$ & FR3 + & - & - & & & \\
\hline 26 & PR1 & $<5 \%$ & FR3 + & - & - & - & - & \\
\hline 27 & PR1 & $<5 \%$ & FR3 + & NA & - & - & - & \\
\hline 28 & CR1 & $<5 \%$ & $\mathrm{FRl}+$ & - & -- & - & - & \\
\hline 29 & CR1 & $<5 \%$ & $\mathrm{FR} 1+$ & - & - & - & - & \\
\hline
\end{tabular}

Status = disease status prior to mobilisation; Ref=disease refractory to VAMP chemotherapy; $\% \mathrm{PC}=$ percentage of plasma cells in bone marrow prior to mobilisation; $\mathrm{PB}=\mathrm{PCR}$ result from peripheral blood taken prior to mobilisation; days $1-4=\mathrm{PCR}$ resuts obtained from the PBPC collected on consecutive days. $+=$ clonal band detected; $-=$ polyclonal result; NA $=$ no sample available. * The bone marrow aspirates from these patients showed less than $10 \%$ plasma cells, but examination of the trephine biopsy specimens revealed significant residual infiltration. 

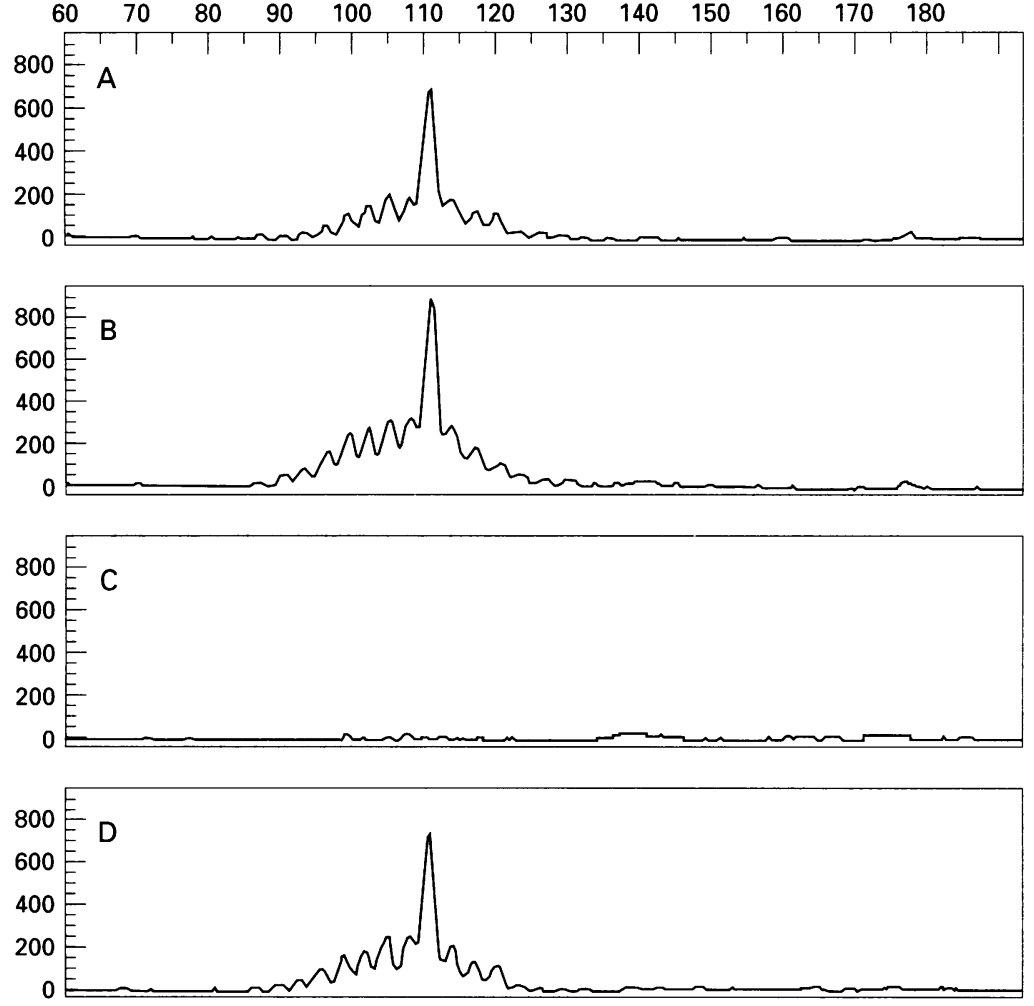

Figure 3 CD34 selection: PCR analysis showing clear evidence of a "clonal purge". The $P B P C$ collected on consecutive days show contamination with an $111 \mathrm{bp}$ clonal IgH rearrangement $(A$ and $B)$. This is absent from the $C D 34$ selected product $(C)$ and seems to be confined to the column waste (D).
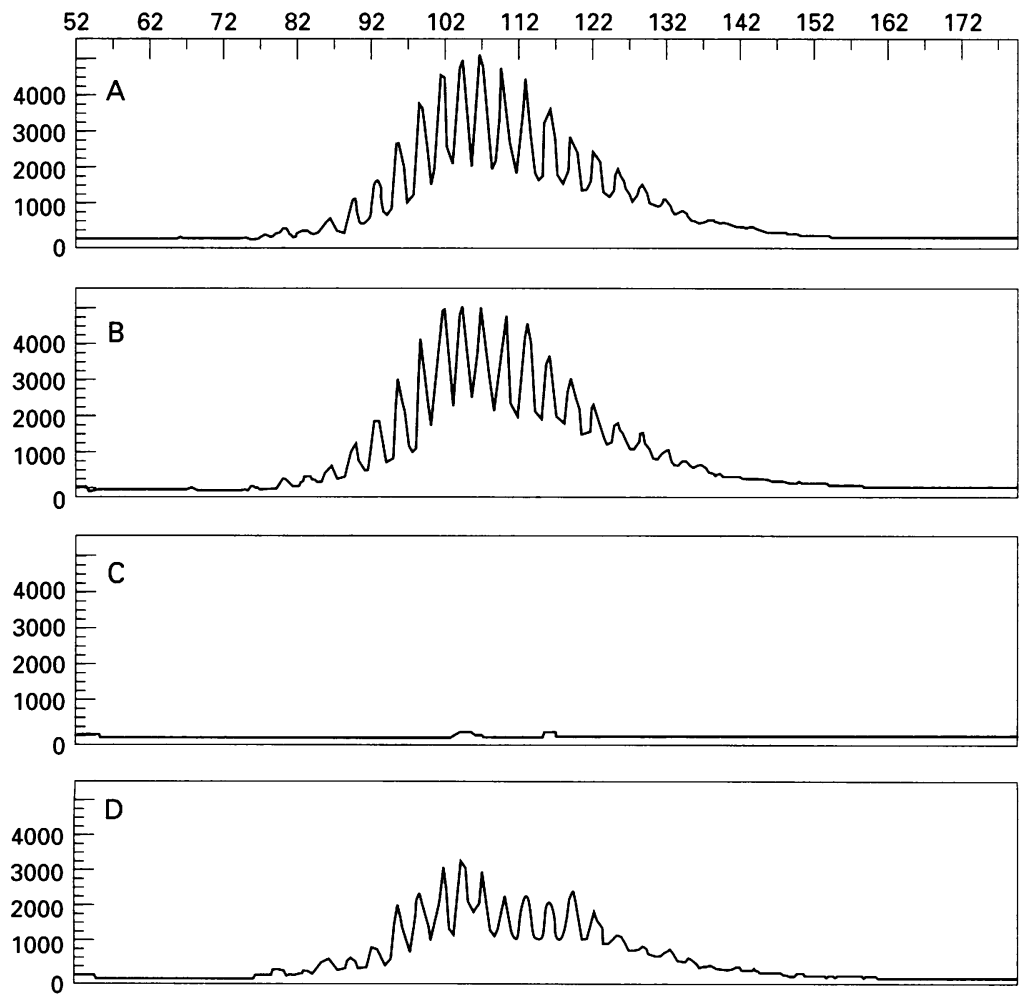

Figure 4 CD34 selection: PCR analysis demonstrating the elimination of $B$ cells. $A$ polyclonal "fingerprint" is obtained from the leucapheresis products ( $A$ and $B)$ and the unabsorbed waste (D), but not from the CD34 selected product (C).
Such rearrangements were not detected in the peripheral blood of any patient analysed prior to PBPC mobilisation, but 10 (35\%) of 29 had detectable rearrangements in their harvested material (table 1). Clonal rearrangements were found in those patients with significant residual bone marrow disease - that is, those patients with greater than $10 \%$ residual plasma cells in a bone marrow aspirate obtained prior to PBPC mobilisation or a persistent infiltrate on the trephine biopsy specimen, or both. Residual bone marrow infiltration was evident in 13 patients; clonal IgH rearrangements were found in the PBPC collections of 10 of the 13 patients. Clonal rearrangements were not detected in the PBPC of the remaining 16 patients who had no evidence of persisting bone marrow disease. In all cases the clonal band seen in the leucapheresis products was identical in size with that seen in the presentation bone marrow sample.

CD34 selection, using an avidin-biotin immunoabsorption column, was carried out in eight patients. Clonal IgH rearrangements were seen in the unmanipulated PBPC of two of these eight patients; in both cases a definitive "clonal purge" was seen as the clonal rearrangement, was not demonstrable in the CD34 positive fraction and seemed to be confined to the column waste (fig 3). A normal polyclonal "fingerprint" could be demonstrated in the CD34 positive fraction of another two patients, suggesting incomplete elimination of contaminating $B$ cells in these patients. In the four remaining patients, however, the polyclonal "fingerprint" was absent. This is consistent with a considerable reduction, if not complete elimination of the contaminating B cells (fig 4).

\section{Discussion}

By using both the CDRIII and CDRI PCR techniques it was possible to demonstrate definitive clonal rearrangements in the presentation bone marrow of over $70 \%$ of patients with multiple myeloma and MGUS. Similar techniques have demonstrated clonal rearrangements in up to $95 \%$ of patients with acute lymphobastic leukaemia. ${ }^{6}$ The methods used are therefore applicable to most patients with multiple myeloma and will detect a rearrangement when a single clonal cell is present in a background of $10^{3}-10^{4}$ normal cells.

At presentation, clonal rearrangements identical with those seen in the bone marrow were detected in the peripheral blood of $50 \%$ of patients with multiple myeloma, which is consistent with previous studies using Southern blotting ${ }^{7-9}$ and immunophenotyping. ${ }^{1011}$ However, with the use of sensitive, allele specific PCR, clonal rearrangements can be demonstrated in the peripheral blood of almost all patients at time of diagnosis. ${ }^{1213}$ Clonal rearrangements were not detected in the peripheral blood of any of our patients tested prior to PBPC mobilisation. In our experience clonal rearrangements disappear quickly from the peripheral blood in patients responding to chemotherapy. However, almost $40 \%$ of patients had clearly detectable clonal rearrangements in 
their PBPC, suggesting that clonal cells had been recruited from the bone marrow by the mobilisation procedure.

This contamination seemed to occur in those patients with significant residual bone marrow disease, suggesting that it is important to achieve the maximum response to treatment before attempting PBPC mobilisation. In our experience it is still possible to obtain sufficient numbers of PBPC after six or more courses of C-VAMP even if CD34 selection is to be undertaken. ${ }^{14}$ In all cases the clonal band detected was identical in size with that seen in the presentation material, which is highly suggestive of clonal cell contamination, particularly in view of the fact that in multiple myeloma the sequence of IgH rearrangements remains unchanged throughout the course of the disease. ${ }^{15}$

Clonal gene rearrangements have also been demonstrated in the PBPC of patients with non-Hodgkin's lymphoma ${ }^{4}$ and acute lymphoblastic leukaemia. ${ }^{16}$ This phenomenon is not confined to lymphoid malignancies. Indeed, tumour cells have been demonstrated by immunocytochemistry in the PBPC of patients with breast and small cell lung cancer. ${ }^{5}$

These increasing data regarding PBPC contamination indicate a need for evaluation of purging strategies. However, the clinical effect of re-infusing clonal cells which contaminate PBPC remains unknown. Clonal cells contaminating autologous bone marrow have been shown to contribute to relapse in a small number of paediatric patients with acute myeloid leukaemia ${ }^{17}$ and neuroblastoma. ${ }^{18}$ Additionally, Gribben et $a l^{19}$ have shown that purging autologous bone marrow (to PCR negativity) in follicular lymphoma can lead to a significant improvement in disease free survival.

Tumour cell depletion can be achieved by selecting haematopoietic progenitors by virtue of their expression of CD $34,{ }^{2021}$ an antigen that does not seem to be expressed in multiple myeloma. ${ }^{22}$ We have evaluated the Ceprate avidin-biotin immunoabsorption column in eight patients with multiple myeloma. As predicted from PCR analysis of PBPC, only two of eight had detectable rearrangements in their harvested material prior to CD34 selection. A definitive "clonal purge" was seen in both patients as we were unable to demonstrate the clonal rearrangement in the CD34 positive fraction. The column also seemed to reduce $B$ cell contamination significantly in four of six patients without clear evidence of a clonal rearrangement in their unmanipulated PBPC. We have also assessed CD34 selection in a further four patients with follicular lymphoma who had clearly contaminated PBPC. A "clonal purge" was seen in three of these cases, while the CD34 positive fraction remained contaminated in the remaining patient (unpublished data). Purging of contaminating clonal cells to below a level of $10^{-4}$ has therefore been demonstrated in five of six patients with contaminated PBPC.

The most fundamental issue, however, is the clonogenicity of these contaminating cells. It is interesting to note that myeloma cells contaminating PBPC seem to have an immature phenotype and higher labelling indexes when compared with bone marrow plasma cells. ${ }^{23}$ This suggests that there is increased cell division and possibly a greater potential for relapse than in the mature, non-dividing bone marrow plasma cells.

In this study we have been able to demonstrate the presence of clonal IgH rearrangements in the PBPC of patients with multiple myeloma and also that cells carrying these rearrangements can be purged successfully (at least in the majority of cases) by CD34 selection. Ultimately, however, it will be only through the demonstration of an improvement in clinical outcome that it will be possible to justify the routine clinical use of such selection procedures.

This work was supported by the Leukaemia Research Fund of Great Britain and the Yorkshire Cancer Research Campaign.

1 Gore ME, Selby PJ, Viner C, Clark PI, Meldrum M, Milla $\mathrm{B}$, et al. Intensive treatment of multiple myeloma an criteria for complete remission. Lancet 1989;ii:879-82.

2 Attal M, Harousseau JL, Stoppa AM, Sotto JJ, Fuzibet G Rossi JF, et al. High dose therapy in multiple myeloma: a prospective randomised study of the "Intergroupe Francais du myelome" (abstract). Blood 1994;84(Suppl 1):386a.

3 Bird JM, Bloxham D, Samson D, Marcus RE, Russell $\mathrm{NH}$, Kelsey SM, et al. Molecular detection of clonally rearranged cells in peripheral blood progenitor cell harvests from multiple myeloma patients. Br 7 Haematol 1994;88: from multip

4 Hardingham JE, Kotasek D, Sage RE, Dubrovic A, Gooley T, Dale BM. Molecular detection of residual lymphoma cells in peripheral blood stem cell harvests and following autologous transplantation. Bone Marrow Transplant 1993 11:15-20.

5 Brugger W, Bross KJ, Glatt M, Weber F, Mertelsman R, Kanz L. Mobilisation of tumour cells and haematopoietic progenitor cells in peripheral blood of patients with solid tumours. Blood 1994;83:636-40.

6 Evans PAS, Shiach CR, Short MA, Morgan GJ, Kinsey SE, Lewis IJ, et al. Use of an automated genescanner to evaluate immunoglobulin gene rearrangements in serial samples from children with ALL. Br f Haematol 1994;86: (Suppl 1):19.

7 Berenson J, Wong R, Kim K, Brown N, Lichtenstein A. Evidence for peripheral blood B lymphocyte but not $T$ lymphocyte involvement in multiple myeloma. Blood 1987 70:1550-3

8 Chiu EKW, Ganeshaguru K, Hoffbrand AV, Mehta AD Circulating monoclonal B lymphocytes in multiple myeloma. Br F Haematol 1989;72:28-31.

9 Van Riet I, Heirman C, Lacor P, DeWaele M, Thielemans K, Van Camp B. Detection of monoclonal B lymphocytes in bone marrow and peripheral blood of multiple myeloma patients by immunoglobulin gene rearrangement studies. Br f Haematol 1989;73:289-95.

10 Jensen GS, Mant MJ, Belch AJ, Berenson JR, Reuther BA, Pilarski LM. Selective expression of CD45 isoforms defines CALLA + monoclonal $B$ lineage cells in peripheral blood from myeloma patients as late stage B cells. Blood 1991;78:711-19.

11 Witzig TE, Kyle RA, Greipp PR. Circulating peripheral blood plasma cells in multiple myeloma. Curr Top Microbio Immunol 1992;182:195-9.

12 Billadeau D, Quam L, Thomas W, Kay N, Griepp P, Kyle $\mathrm{R}$, et al. Detection and quantitation of malignant cells in the peripheral blood of multiple myeloma patients. Blood 1992;80:1818-24.

13 Corradini P, Voena C, Omede P, Astolfi M, Boccadoro M, Dalla Favera $\mathrm{R}$, et al. Detection of circulating tumour cells in multiple myeloma by a PCR based method. Leukcells in multiple myeloma

14 Johnson RJ, Owen RG, Smith GM, Child JA, Galvin M Newton LJ, et al. Peripheral blood stem cell transplantation in myeloma using CD34 selected cells. Bone Marrow in myeloma using CD34

15 Ralph QM, Brisco MJ, Joshua DE, Brown RD, Gibson J Morley AA. Advancement of multiple myeloma from diagnosis through plateau phase to progression does no involve a new $\mathrm{B}$ cell clone: evidence from the Ig heavy chain gene. Blood 1993;82:202-8.

16 Owen RG, Johnson RJ, Evans PA, Smith GM, Child JA Morgan GJ. Detection of clonal immunoglobulin gene rearrangements in the PBPC harvests of patients with acute lymphoblastic leukaemia. Bone Marnow Transplant 1995;16:831-4.

17 Brenner MK, Rill DR, Moen RC, Krance RA, Mirro JJ, 
Anderson WF, et al. Gene marking to trace the origin of relapse after autologous bone marrow transplantation. Lancet 1993;341:85-6.

18 Rill DR, Santana VM, Roberts WM, Nilson T, Bowman LC, Krance RA, et al. Direct demonstration that autologous bone marrow transplantation for solid tumors can return a multiplicity of tumorigenic cells. Blood 1994;84: 380-3.

19 Gribben JG, Freedman AS, Neuberg D, Roy D, Blake K Woo $S$, et al. Immunologic purging of marrow assessed Woo $S$, et al. Immunologic purging of marrow assessed for B-cell lymphoma. N Engl ₹ Med 1991;325:1525-33.

20 Schiller G, Vescio R, Freytes C, Spitzer G, Sahebi F, Lee M, et al. Transplantation of CD $34+$ peripheral blood progenitor cells after high-dose chemotherapy for patients with advanced multiple myeloma. Blood 1995;86:390-7. 21 Gazitt Y, Reading CC, Hoffman R, Wickrema A, Vesole $\mathrm{DH}$, Jaganath S, et al. Purified CD $34+$ Lin- Thy + stem cells do not contain clonal myeloma cells. Blood 1995;86 381-9.

22 Vescio RA, Hong $\mathrm{CH}$, Cao J, Kim A, Schiller GJ Lichtenstein AK, et al. The haematopoietic stem cell antigen, CD34 is not expressed on the malignant cells in antigen, CD34 is not expressed on the malign
multiple myeloma. Blood 1994;84:3283-7.

23 Gibson J, Pope B, Peterson A, Brown R, Jameson S, Luo XF, et al. GCSF stimulated PBSC harvests in myeloma contain immature malignant plasma cells (abstract). Blood 1994;84(Suppl 1):108a. 